\title{
Necrofagia, abyección, tabú y muerte del genio: una hipótesis de lectura de "Carne", de Mariana Enríquez
}

\author{
María Sánchez Cabrera ${ }^{1}$
}

Resumen. En su relato "Carne", Mariana Enríquez tematiza uno de los tabúes mejor asentados en nuestra cultura: el de la necrofagia. El objetivo de este artículo será exponer cómo la tradicional inmunidad de los muertos, así como la prohibición de consumir carne humana, es conquistada y subvertida en la narración. De lo anterior se desprende una noción del horror vinculada a la abyección, al ritual y al tabú (en este caso, al de la deglución y al del contacto con lo muerto) que resulta de especial interés en la narrativa de Enríquez. Y es que, en última instancia, el cuerpo humano es concebido como objeto de consumo; el ídolo de masas, como propiedad pública.

Palabras clave: carne; necrofagia; cuerpo; ídolo; horror.

[en] Necrophagy, abjection, taboo and death of the genius: a reading hypothesis of "Carne", by Mariana Enríquez

\begin{abstract}
In her short story "Carne", Mariana Enríquez works with one of the best stablished taboos of our culture: necrophagy. This article intends to show how the traditional immunity of the death, along with the interdiction of consuming human flesh, are conquered and subverted. From all of the above, we infer that the notion of horror is linked to the notions of abjection, ritual and taboo (in this case, the taboo imposed to swallowing and contact with what is death). These notions are of special interest in the works of Enríquez. To sum up, human body is regarded as an object to be consumed; the idol of masses is conceived as a public property.
\end{abstract}

Keywords: flesh; necrophagy; body; idol; horror.

Cómo citar: Sánchez Cabrera, M. (2021) Necrofagia, abyección, tabú y muerte del genio: una hipótesis de lectura de "Carne", de Mariana Enríquez, en Anales de Literatua Hispanoamericana 50, 409-414.

En el contexto de la narrativa hispanoamericana contemporánea, la obra de Mariana Enríquez (Buenos Aires, 1973) ha sido especialmente reseñada. Su relato "El aljibe" figura entre las páginas de La joven guardia: nueva literatura argentina (2009), una antología en el que también aparecen, con sus respectivas propuestas, autores como Samanta Schweblin o Juan Terranova. El objetivo del libro, en palabras de Maximiliano Tomás, fue la "ingrata tarea de establecer un nuevo canon" (2009: 9); un canon que ya es conocido como "nueva narrativa argentina", o más comúnmente, por sus siglas NNA. Sin embargo, y amén del relativo anonimato de algunos autores en aquel momento, pocos son los rasgos que comparten. Tomás advierte de su deliberada renuncia a buscar afinidades estilísticas en estos narradores; en lugar de esto, los agrupa en torno a otros elementos:

Haber nacido en la Argentina a partir de 1970 (es decir, contar como máximo con 35 años a la fecha de aparición del libro); tener al menos una obra publicada o en proceso de publicación; y, sobre cada una de

\footnotetext{
${ }^{1}$ Universidad Autónoma de Madrid. Madrid.

E-mail: mariasanchezcab@gmail.com
} 
ellas, la fundamental: sin distinción de corrientes, escuelas, programas ni estilos, que los textos tuvieran una evidente calidad literaria $(9)^{2}$.

De lo anterior se desprende que la producción de Enríquez puede no ser analizada desde una perspectiva sincrónica. Su obra no discurre por los mismos raíles que la de sus coterráneos, pero sí mantiene una coherencia interna en cuanto a los temas que la obseden; desde esta recurrencia temática podemos iniciar un acercamiento analítico. Si hubiera que sistematizar su narrativa, cabría indicar que combina distintas proporciones de terror y realismo. Su universo literario es el de la cotidianidad convertida en horror; una poética cercana al cuento fantástico y que se vuelca fundamentalmente en sus relatos breves ${ }^{3}$. En ellos, los motivos recurrentes de la literatura gótica (casas encantadas, aparecidos, magia negra) van de la mano de las ficciones policiales y de un expresionismo crudo y visceral. Sin embargo, y pese a mostrar sin ambages sus referentes literarios, los relatos de Enríquez no aceptan una adscripción fácil a estas tradiciones. La autora recurre a la literatura de género para abastecer su arsenal literario, pero el propósito, antes que sembrar horror, sería trasladar esos motivos a una realidad que ya no se concibe estable, segura y previsible.

La crítica orientada al examen de lo fantástico ha señalado que el relato gótico tradicional, a la manera del siglo XVIII, ha perdido su poder transgresor; esta potencialidad, tan eficaz en el contexto del racionalismo ilustrado, no resulta operativa en épocas más cercanas (Roas, 2001: 24). El lector contemporáneo descree de fantasmas, vampiros y apariciones sobrenaturales, y esta afirmación, aparentemente perogrullesca, tiene un calado fundamental en la evolución de un género que juega con el horizonte de creencias de su público. Volviendo a Roas (14), el contexto sociocultural es importante en la medida en que condiciona qué se entiende por transgresión (Campra: 2001), vacilación (Todorov: 1980), ominoso (Freud: 1992b) y otros conceptos que baraja la crítica. Lo fantástico, para seguir siendo contraste de la realidad ${ }^{4}$, debe evolucionar en paralelo a su tiempo y así lo hace durante el pasado siglo.

De esta manera, el relato de ficción fantástica adopta, también en Enríquez, formas que sin ser "fantásticas" en sentido estricto sí son capaces de suscitar el mismo efecto en los lectores: la historia argentina ("Chicos que faltan") los secretos familiares ("El aljibe"), la locura ("Fin de curso"), la paranoia colectiva ("Las cosas que perdimos en el fuego"). Lo sustancial no varía: el terror nace cuando se hace efectivo lo que se creía imposible. Y en ocasiones este imposible adquiere la forma de lo culturalmente negado u oprimido: "Lo "otro" expresado a través de la fantasía ha sido categorizado como un área oscura y negativa - como el mal, lo demoníaco o lo bárbaro-, hasta que en lo fantástico moderno se lo ha reconocido como lo "oculto" en la cultura" (Jackson, 2001: 144).

Un ejemplo de este socavamiento de las convenciones culturales lo encontramos en "Carne", incluido en Los peligros de fumar en la cama (2017). En este relato, Enríquez no hace uso de aparecidos o torceduras del binomio espacio-tiempo, sino de la abyección casi universal que supone alimentarse de otra persona. Al canibalismo, "cortocircuito cultural y moral" (Pancorbo, XVII), se une la necrofagia, la automutilación y el suicidio. Estos hechos aparecen, además, revestidos de cierta religiosidad e incluso mesianismo, involucrando y violentando nuestras asunciones con respecto al carácter sagrado del cuerpo humano, la inmunidad de los muertos y el papel del arte en la creación de la identidad del individuo y del grupo.

El argumento gira en torno a Santiago Espina, un cantante de rock de la escena underground de Buenos Aires. En él se aúna la ambivalencia entre el visionario y el ídolo de masas, entre el virtuoso y el producto mercantil, que parece recurrente en el mundo de la música: "Santiago, a quien la prensa especializada amaba y odiaba a partes iguales: genio, pretencioso, artista inclasificable, artefacto comercial para hipnotizar niñas alienadas, idiota caprichoso" (126). Tras el tímido renombre de su primer disco, su segundo trabajo, Carne, es un éxito de ventas inesperado, lo que permite a los productores augurar un despegue internacional. Sin embargo, el cadáver mutilado de Espina aparece en una habitación de hotel, fruto de un suicidio espeluznante: "había usado una gilette y un Tramontina a conciencia para despellejarse los brazos, las piernas, el vientre. En el brazo izquierdo, había cortado hasta el hueso. En el pecho era posible ver el

\footnotetext{
${ }^{2}$ Con respecto a estos rasgos no compartidos, Elsa Drucaroff ha completado el ejercicio antológico de Tomás aventurándose a establecer analogías formales. Véase "Nueva narrativa argentina. Relatos de los que no se la creen", en el suplemento Cultura del diario Perfil de Buenos Aires, con fecha del 19 de agosto de 2007.

${ }^{3}$ La observamos también reflejada en su crónica Alguien camina sobre tu tumba: mis viajes a cementerios (2013) y sus novelas Chicos que vuelven (2011) y la reciente Este es el mar (2017), que amplia y detalla el fanatismo, la fascinación por lo morboso y la fuerza de la pulsión sexual adolescente que ya aparecen en "Carne".

4 “[...] el concepto de "fantástico" se define solamente en negativo: es aquello que no es". (Campra, 2001: 154).
} 
esternón. Y, posiblemente semiinconsciente, se había cortado la yugular con un tajo audaz y preciso. No se había mutilado la cara" (127). El músico había dejado el aire acondicionado encendido para conservar su cuerpo en perfecto estado, así como una inquietante nota de suicidio: "Carne es comida. Carne es muerte. Ustedes saben cuál es el futuro" (127). Este fallecimiento violento conmociona a sus incondicionales pero, tras el entierro, todo parece calmarse. "Nadie podía suponer que algo se estaba gestando en Mataderos, entre dos chicas, una foto arrugada de la nota suicida y Carne en el equipo, de principio a fin, una y otra vez". (128).

Estas dos chicas, Mariela y Julieta, comparten su fervor por Espina. La primera le ha seguido desde sus inicios; la segunda ha llegado a tatuarse su nombre en el cuello. Esta devoción no solo las ha hecho conocidas entre las "espinosas", las fanáticas del cantante, sino que las ha llevado a incluso a parecerse físicamente. Una noche, el cuidador del cementerio donde habían enterrado al ídolo las encuentra tratando de escapar. Pocas horas antes, las adolescentes habían asaltado la tumba del músico y devorado sus restos putrefactos hasta dejar limpios los huesos. Comienza entonces "la mayor histeria jamás vista" (125); el narrador, que se limita a contar lo que se filtra a los medios, solo transmite que las jóvenes se niegan a dar cuenta de lo que han hecho mientras sonríen enigmáticamente a las cámaras. Esta actitud empieza a contagiarse al resto de las espinosas; en televisión, una de ellas declara envidiar a las caníbales porque "ellas lo entendieron" (131). Y las muchachas, tras haber sido dadas de alta en el hospital psiquiátrico, son forzadas por sus familias a apartarse de la escena pública, a dejar el colegio y a interrumpir todo contacto con la otra.

Y sin embargo, las cientos de espinosas del país comienzan a recibir misteriosos correos electrónicos que guardan celosamente en secreto. Incapaces de identificar al remitente, solo pueden especular con su contenido. El relato finaliza tal y como exponemos:

Los mails hablaban de dos chicas que pronto cumplirían dieciocho años y se liberarían de padres y médicos para tocar las canciones de Carne en sótanos y garajes. Hablaban de un culto subterráneo imparable, de Ellas Las Que Tenían Espinas en el cuerpo. Las fans esperaban con brillantina en las mejillas, las uñas pintadas de negro y los labios manchados de vino tinto el mensaje que les diera la fecha y el lugar de la segunda venida, el mapa de la tierra prohibida. Y escuchaban la última canción de Carne (donde el Espina susurraba "Si tenés hambre, comé de mi cuerpo. Su tenés sed, bebé de mis ojos") soñando con el futuro (133).

Como viene siendo usual en sus relatos, Enríquez interrumpe la narración en el momento de clímax narrativo ("Dónde estás corazón", "Fin de curso", "El patio del vecino", etc.). Tras haber proporcionado todos los datos y haber guiado al lector al desenlace, este queda convocado a resolver el único posible, del que ya es partícipe y casi dueño. Con "Carne", los lectores han presenciado la violación del tabú de la muerte y de la ingesta de carne humana. La comunión con lo que podemos llamar un "padre espiritual", al abrigo del secreto, es principio y fundación de un orden cultural nuevo, fuera de los límites de control social. El horror, como vemos, se extrae del tabú y de la sublimación de un hecho que se nos antoja impensable, pero a la vez, y esta es nuestra tesis, más que familiar.

$\mathrm{Y}$ es que pocas prohibiciones hay tan arraigadas en nuestra cultura como la de alimentarse de la carne de otro ser humano. Sigmund Freud, en "El porvenir de una ilusión" (1992a: 5-55), indica que, de entre los tres deseos primarios de la psique -el incesto, el homicidio y el canibalismo-, tan solo este último "es unánimemente condenado $\mathrm{y}$, salvo para la observación psicoanalítica, parece haber sido dominado por completo" (11). Y sin embargo, recuerda este autor, el canibalismo forma parte de la vida psíquica humana y puede darse como práctica gastronómica y ritual. Tempranamente, autores como William Arens (1979) negaron que el canibalismo existiera salvo como ficción colonial, pero esta conclusión fue descartada: la antropofagia existió, existe y no necesariamente como casos aislados ${ }^{5}$. Conviene, por ello, detenerse a analizar las perspectivas, a veces contradictorias, con la que los estudios académicos han abordado esta cuestión. Julián López García (2012: 120) recoge tres aproximaciones: la psicógena, la materialista y la culturalista. Según la hipótesis psicógena, el canibalismo es una forma de agresión institucionalizada y sublimada que satisface algunas necesidades psicosexuales (Sagan, 1974). La hipótesis materialista de Harner (1977) y Harris (1985) indica que está motivado por razones ambientales y de estricta supervivencia. Por último, hay quienes afirman que el canibalismo es una práctica cultural que jamás se da exclusivamente por hambre, y que en todo caso es un elemento social susceptible de estudios antropológicos. Entre estos trabajos se destaca el de Peggy Reeves Sanday. En su obra El canibalismo como cuestión cultural (1986), la 
autora desestima la idea de que este aparezca originado únicamente por razones adaptativas o utilitarias. La escasez de alimentos, si bien puede inducir a la antropofagia, no da cuenta su dimensión ontológica, pues en las sociedades donde se practica aparece codificado socialmente, tiene funciones psicológicas y se vincula a lo simbólico o lo sexual, sirviendo, además, a la construcción del yo y del colectivo: "el canibalismo nunca tiene que ver con el hecho de comer, sino que es, ante todo, un vehículo para mensajes no gustativos, mensajes que tienen que ver con el mantenimiento, la regeneración y, en algunos casos, con la fundación del orden cultural" (1986: 18).

Este enfoque es el adecuado para analizar el canibalismo en Enríquez. Las jóvenes que se alimentan de Espina no están movidas por una necesidad fisiológica, sino por deseos que nos parecen primitivos e incomprensibles. Sin embargo, tales impulsos encuentran resonancia en algunos autores vinculados al psicoanálisis, muy especialmente en aquellos que abordan el análisis cultural desde estos presupuestos. Se hace inevitable mencionar a Julia Kristeva y a su ya canónico ensayo "Los poderes de la perversión” (2006). En él, la autora explora las posibilidades de "lo abyecto" como perspectiv analítica. Abyecto sería todo aquello que el individuo debe rechazar para componer su identidad; aquello que, una vez expulsado, colinda los límites de dicha integridad, amenazándola. Su dimensión escapa lo estrictamente individual: es abyecto también aquello que puede romper o cuestionar un órganon, un sistema de creencias, un código de significación. En palabras de Kristeva, el cadáver sería "el colmo de la abyección” (11) por colindar con la condición de lo vivo, por ser lo que ha de descartarse para vivir. Y sin embargo, "el asco por la comida es la forma más elemental y más arcaica de la abyección" (9).

Resulta interesante a nuestros propósitos el vínculo que la autora establece entre la comida y el cadáver. Si esta primera es la forma más primitiva de la abyección, y el segundo es la más plena, el resultado de ingerir un cuerpo en descomposición no puede ser otra cosa que una abyección superlativa, que cubre todo el espectro de lo abyecto. También Freud se ocupa de estas cuestiones, con conclusiones semejantes, en su ensayo "Tótem y tabú" (1992c). En él se indica que dos de las funciones básicas del tabú cultural son "preservar al sujeto de los peligros resultantes del contacto con cadáveres" y "de la absorción de determinados alimentos" (28). Para Freud, la comida y el cuerpo muerto también están psíquicamente relacionados. Y es que, como indica Cunillera Pérez, lo abyecto "se identifica con lo excluido y los tabúes" (2009: 218). Esta estrategia transgresora se plasma con eficacia en el relato de Enríquez; en el momento en el que las jóvenes engullen el cuerpo semidescompuesto de su ídolo, el tabú contra estas prácticas queda roto.

Pero, ¿qué es, para Freud, un tabú? El tabú lo componen una serie de limitaciones a las que someten los pueblos primitivos, ignorando sus razones y sin preocuparse de buscarlas, pero considerándolas perfectamente naturales. Estos grupos humanos están, además, convencidos de que la violación del tabú acarrearía terribles castigos; esta prohibición, social y paterna, solo recae sobre las actividades que inspiran un intenso deseo colectivo (39). Kristeva indica que el peligro de lo abyecto radica precisamente en su ambivalencia, en su capacidad para provocar rechazo y atracción (8). El tabú así entendido implica la existencia de una tendencia insubordinable, natural y general hacia ciertos comportamientos considerados abyectos. Pero si el individuo quiere, pues así lo necesita, convertirse en ciudadano, debe reprimir sus deseos abyectos de destrucción de su identidad social. El tabú cumple una función preservadora de la unidad de estos códigos de significación: el tabú es, por definición, restrictivo. Y su transgresión, vuelve a indicar Kristeva, provoca horror, pues está emparentado con la perversión (25). Resulta interesante comprobar cómo, aunque el relato menciona la tristemente famosa tragedia de los Andes ${ }^{6}$, uno de los supervivientes del vuelo indicó que había que diferenciar "su antropofagia "por necesidad" de "esta locura" (132). A las prácticas antropófagas motivadas por hambre se las conoce como "canibalismo blanco" y, en efecto, la restricción del tabú no parece aplicarse a ellas con la misma fuerza. Es necesario, para esto, que exista un deseo no vinculado a la supervivencia; un deseo orientado a satisfacer necesidades menos prosaicas y, a la vez, sublimes.

La mentada ambivalencia de lo abyecto alcanza un sentido más profundo en la medida en que, en palabras de Kristeva, "lo abyecto puede aparecer como la sublimación más frágil, más arcaica de un "objeto" todavía no separado de las pulsiones" (21). Freud también se hace eco de esta dimensión excelsa de la abyección cuando indica que "el canibalismo de los primitivos presenta una análoga motivación sublimada.

\footnotetext{
${ }^{6}$ Nos referimos al accidente que tuvo lugar en 1972, cuando un avión en el que viajaba un equipo de rugby uruguayo y algunos amigos y familiares se estrelló en la cordillera de los Andes. A 4000 metros de altitud, en condiciones extremas, los supervivientes comieron los restos mortales de sus compañeros, familiares y amigos hasta que fueron rescatados.
} 
Absorbiendo por la ingestión partes del cuerpo de una persona, se apropia el caníbal de las facultades de que la misma se hallaba dotada" (1992c: 85). Y es que "la vida vuelve, nuevo significado, con la comida. El canibalismo mortuorio, por ejemplo, transmite la esencia vital" (Reeves Sarday: 57). En lo que parece una vuelta de tuerca premeditada, estos autores señalan que la abyección, además de desintegrar el yo, transforma la pulsión de muerte en arranque de vida, en nuevas significaciones (Kristeva, 24). La tentación de destrucción de la individualidad supone un acto de creación de un orden nuevo. A estas propuestas se une la de Lyotard con su estética de lo sublime (1998). Lo sublime es una categoría de representación llamada a ser ambigua; un juego donde la contradicción rompe los límites del sentido común, enfrenta al sujeto con su propia humanidad y pone en cuestión los límites del entendimiento, de una manera muy similar a como Kristeva define la abyección.

Así, en un acto de sublimación que destruye su unidad, las muchachas de Enríquez comen del cadáver y lo hacen juntas. Compartir alimentos es, como se sabe, un ritual casi universal de unión y fraternidad. Siendo, como eran, parecidas físicamente, este acto las hermana de una forma todavía más profunda ${ }^{7}$. Este ritual alimenticio reviste el acto abyecto de comer, protegiendo el tabú, pero a la vez lo viola, confirmando la ruptura de las muchachas con su contexto cultural. Y sin embargo, este acto también implica el nacimiento de un código de significación diferente. Se hace necesario, en este punto, volver a Freud. La figura del tótem cultural, origen de todo sistema religioso, se vincula a la figura del padre espiritual y adopta diversas formas, todas ellas encarnaciones de esta autoridad. Es usual que los pueblos que practican el totemismo coman la carne del padre en alguna de estas encarnaciones; esta ingesta del tótem, que implica un sacrificio, deviene en sacramento y en ritual, y confirma la unión del individuo con su grupo, con el mundo y con su contexto cultural. Desde esta óptica, la comunión cristiana no sería otra cosa que un ritual de supresión del padre-tótem a través de las encarnaciones vicarias del pan y del vino; un ritual de abyección, de sublimación y de renovación de la fuerza vital: "la vida que reside en su carne y en su sangre se comunica por medio de la comida de sacrificio a todos aquellos que en ellos toman parte" (1992c: 140).

Y este vínculo no sería otra cosa que el cuerpo de la víctima, portador de un principio que el grupo humano necesita poseer y renovar. Pero esta ceremonia tiene lugar, en el relato de Enríquez, entre dos muchachas; no solo excluye al resto de la sociedad sino que además violenta profundamente sus creencias. Este canibalismo mortuorio viola el tabú en un doble acto de destrucción y creación. Comer al padre, comer al líder, implica ocupar su lugar: si, siguiendo a Freud, este es el acto inaugural de toda cultura, estas muchachas están dando luz a una cultura alternativa en el seno de la nuestra, que exhibe los mecanismos de creación que son propios a todas. Kristeva indica que las víctimas de lo abyecto, aquellas que han trascendido los límites de su individualidad, parecen presas de la fascinación (18). Y así, en efecto, se muestran Mariola y Julieta, triunfantes y silenciosas, ante el resto del mundo: ahora son, en efecto, Ellas Las Que Tenían Espinas en el Cuerpo.

La comunión sacramental de las muchachas, gustativa y sexual, tiene mucho que ver con la condición del genio en las sociedades contemporáneas. Baudrillard afirma que el objeto de consumo más bello es hoy el cuerpo humano; es objeto, incluso, de salvación, pues ha sustituido al alma en su función social e ideológica (1974: 155). El genio, fetichizado, deviene en objeto de culto narcisista, o en otras palabras, en elemento de táctica y rito social (159). Este vínculo dionisíaco y corporal con el genio es reseñado por Sebreli (2000) como una religión de la modernidad: la comunión, inspirada por la música, es orquestada por un ídolo que no debe solamente ofrecer su legado artístico, sino también ofrendar su vida, su alma hecha cuerpo, en el altar de su cultura (313). De esta nueva concepción de la carnalidad da buena cuenta el cuerpo robado de Charles Chaplin, el de Eva Perón, el cerebro de Einstein, de Lenin o Rubén Darío, entre otras extrañas reliquias paganas. $\mathrm{Y}$ es que el visionario de la modernidad, aquél que ha sido escogido como ídolo, debe convertirse en carne, en tótem para el consumo colectivo, en padre y patrimonio. Santiago Espina supo sembrar las pistas adecuadas; en efecto, la carne que ofrece es carne de vida, amenaza y fuente de nuevas significaciones, un reclamo escalofriante en tanto que abre la puerta a una cultura alternativa, diferente, que a la vez supone un crudo reflejo de los mecanismos fundacionales de la nuestra. Esta dimensión de lo umheilich freudiano, de lo que, aun siendo familiar, nos resulta extraño y ajeno, sigue suscitando un terror vernáculo pero siempre susceptible de ser actualizado.

\footnotetext{
${ }^{7}$ Enríquez enfatiza en más de una ocasión el vínculo de ambas chicas hasta tal punto que se nos antojan la misma persona. Este efecto disolvente de la identidad también produce desasosiego y se vincula al doble, un elemento de especial recurrencia en la literatura fantástica y de horror. Véase el estudio pionero de Otto Rank (1971).
} 


\section{Referencias bibliográficas}

Arens, Williams (1979). The man-eating myth, anthropology \& anthropophagy. Nueva York: Oxford University Press. Baudrillard, Jean (1974). La sociedad de consumo: sus mitos, sus estructuras. Madrid: Siglo XXI.

Campra, Rosalba (2001), "Lo fantástico: una isotopía de la transgresión”, en Teorías de lo fantástico. Madrid: Arco Libros, págs. 153-191.

Cardín, Alberto (1994). Dialéctica y canibalismo. Barcelona: Anagrama.

Cunillera Pérez, María (2009). Metáforas de la voracidad en el arte del siglo XX. (Tesis doctoral). Universidad Complutense de Madrid: Madrid.

Drucaroff, Elsa (2007), "Nueva literatura argentina. Relatos para los que no se la creen", Cultura (suplemento de Perfil), 19 de agosto.

Enríquez, Mariana (2009). Las cosas que perdimos en el fuego. Barcelona: Anagrama.

---------, --------- (2011). Chicos que vuelven. Buenos Aires: Edivum.

---------, --------- (2016). Alguien camina sobre tu tumba: mis viajes a cementerios. Buenos Aires: Galerna.

(2017). Los peligros de fumar en la cama. Barcelona: Anagrama.

(2017). Este es el mar. Madrid: Mondadori.

Freud, Sigmund (1992a), "El porvenir de una ilusión”, en Obras completas, volumen XXI. Buenos Aires: Amorrortu, págs. 5-55.

------, -------- (1992b), “Lo ominoso”, en Obras completas, volumen XVII. Buenos Aires: Amorrortu, págs. $215-251$.

(1992c), “Tótem y tabú”, en Obras completas, volumen XIII. Buenos Aires: Amorrortu, págs. 1-164.

Gleyse, Jacques (1994). L'instumentalisation du corps: une archéologie de la rationalisation instrumentale du corps, de l'âge classique à l'époque hypermoderne. Paris: L'Ouverture Philosophique.

Harner, Michael (1997), “The enigma of Aztec Sacrifice”, en Natural History, vol. 86, n. 4, págs. 46-51.

Harris, Marvin (1985). Caníbales y reyes: los orígenes de la cultura. Barcelona: Salvat.

Jackson, Rosie (2001), "Lo “oculto" de la cultura”, en Teorías de lo fantástico. Madrid: Arco libros, págs. 141-152.

Kristeva, Julia (2006), “Sobre la abyección”, en Poderes de la perversión: ensayo sobre Louis-Ferdinand Céline. Madrid: Siglo xxi, págs. 7-47.

Le Breton, David (2002). La sociología del dolor. Buenos Aires: Nueva Visión.

Lévi-Strauss, Claude (1968). Lo crudo y lo cocido. México: Fondo de cultura económica. (1995). Antropología estructural. Barcelona: Paidós.

López García, Julián (2012), “Incesto y canibalismo en la reflexión antropológica”, en Equipaje para aventurarse en Antropología: temas clásicos y actuales de la antropología social y cultural. Madrid: Uned Editorial, págs. 101-128.

Lyotard, Jean-François (1998). Lo inhumano. Charlas sobre el tiempo. Buenos Aires: Ediciones Manantial SRL.

Mauss, Marcel (1979). Sociología y antropología. Madrid: Tecnos.

Memmi, Dominique (2004). La revanche de la chair: Essai sur les nouveaux supports de l’iddentité. Paris: Éditions du Seuil.

Métraux, Alfred (2011). Antropofagia y cultura. Buenos Aires: El cuenco de plata.

Moros Peña, Manuel (2008). Historia cultural del canibalismo: un sorprendente recorrido por la antropofagia desde la Antigüedad hasta nuestros días. Madrid: Nowtilus.

Pancorbo, Luis (2008). El banquete humano: una historia cultural del canibalismo. Madrid: Siglo XXI.

Rank, Otto (1971). The double. Carolina del Norte: University of North Carolina.

Reeves Sanday, Peggy (1986). El canibalismo como sistema cultural. Barcelona: Lerna.

Roas, David (2001), "La amenaza de lo fantástico", en Teorías de lo fantástico. Madrid: Arco libros, págs. 7-44.

Sagan, Eli (1974). Cannibalism, Human Agression and Cultural Form. Nueva York: Harper y Row.

Sebreli, Juan José (2000). Las aventuras de la vanguardia: el arte moderno contra la modernidad. Buenos Aires: Sudamericana.

Todorov, Tzvetan (1980). Introducción a la literatura fantástica. México: Premia Editora.

Tomás, Maximiliano (2009). La joven guardia: nueva literatura argentina. Barcelona: Verticales de bolsillo. 